\title{
Left-Sided Amyand Hernia: Case Report and Review of the Literature
}

\author{
Ryan Nowrouzi; Rohit Gupta; and SreyRam Kuy, MD, MHS
}

\author{
Left-sided Amyand hernia is a rare condition that requires a high degree of clinical \\ suspicion to correctly diagnose.
}

\begin{abstract}
Ryan Nowrouzi and Rohit Gupta are Medical Students at Baylor College of Medicine in Houston, Texas. SreyRam Kuy is Deputy Chief Medical Officer for Quality and Safety for US Department of Veterans Affairs Veterans Integrated Service Network 16 in Houston.

Correspondence: Ryan Nowrouzi

(ryan.nowrouzi@bcm.edu)
\end{abstract}

Fed Pract. 2021;38(6) Published online June 15 doi:10.12788/fp.0136
7 he presence of the vermiform appendix within an inguinal hernia sac is termed an Amyand hernia. While the incidence of Amyand hernia in the general population is thought to be exceedingly rare, the presence of a left-sided Amyand hernia is even more rare due to the normal anatomical position of the appendix on the right side. Left-sided Amyand hernia presents a novel diagnosis that necessitates a high degree of clinical suspicion and special consideration during patient workup and operative treatment. We describe such a case and provide a review of all reports in the literature of this rare finding.

\section{CASE PRESENTATION}

A male aged 62 years presented to the emergency department of the Michael E. DeBakey Veterans Affairs Medical Center in Houston, Texas, in acute distress after experiencing 5 days of nausea and pain in his lower abdomen. The patient's history was significant for cocaine abuse and a left-sided inguinal hernia that was repaired about 15 years prior to this visit. He reported having no bowel movements for the past 5 days and no other symptoms, including vomiting, hematemesis, and trauma to the abdomen. The patient's abdominal pain was located in the suprapubic and periumbilical regions. Upon palpation of the lower abdomen, a firm, protruding mass was identified in the left lower quadrant and suspected to be a left-sided inguinal hernia.

A scout film and computed tomography (CT) scan of the abdomen taken on the same day that the patient presented to the emergency department confirmed the presence of a large left-sided inguinal hernia with possible bowel strangulation involving the colon (Figures 1, 2, and 3). The patient was diag- nosed with an incarcerated recurrent left inguinal hernia and was taken emergently to the operating suite. General anesthesia and an ilioinguinal nerve block were performed. An inguinal incision was made on the left side, and the large hernia sac was identified and separated from the scrotum and spermatic cord structures.

On visual inspection, the hernia was identified as both a direct and an indirect inguinal hernia, making it a pantaloon hernia. The hernia sac was opened, and contents of the herniated sac were found to include the omentum, a loop of transverse colon, as well as the entire cecum and appendix, confirming the diagnosis of an Amyand hernia (Figure 4). Though the bowel was initially dusky, all the bowel became pink and appeared to be viable after detorsion of the bowel. Diagnostic laparoscopy through a 5-mm port was performed to assess the remainder of the bowel located intra-abdominally. The remaining intra-abdominal bowel appeared healthy and without obvious signs of ischemia, twisting, or malrotation. The large hernia defect was repaired with a polypropylene mesh.

\section{DISCUSSION}

An Amyand hernia is an inguinal hernia in which the vermiform appendix is located within the hernial sac. Named after the French surgeon Claudius Amyand who first documented such a case during an appendectomy in 1735, the Amyand hernia is rare and is thought to occur in $<1 \%$ of inguinal hernias. ${ }^{1}$ Given the normal anatomical position of the appendix on the right side of the body, most Amyand hernias occur in a right-sided inguinal hernia.

A literature review yielded 25 reported instances of a left-sided Amyand 
FIGURE 1 Preoperative Large Scrotal Component of Left-Sided Hernia

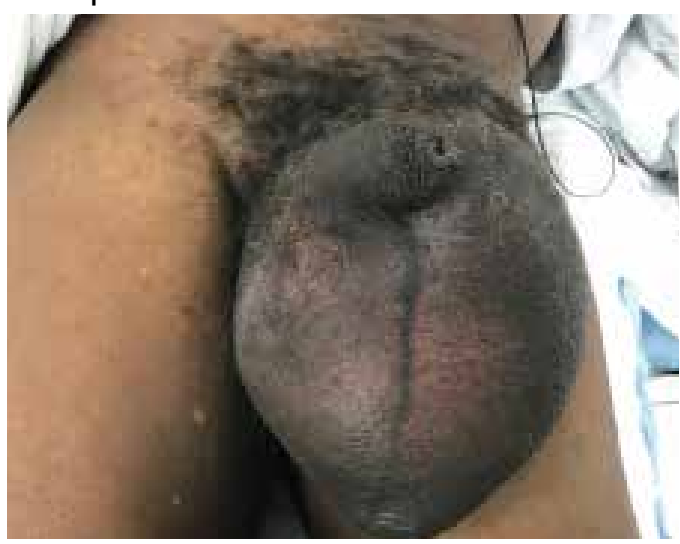

FIGURE 3 X-ray of Large Shadow of Hernia Sac on Left Side

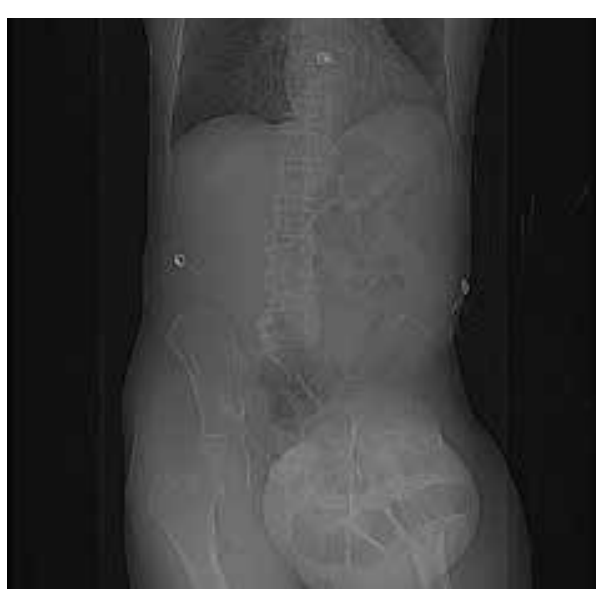

FIGURE 4 Intraoperative Image Showing Presence of Appendix in Opened Hernia Sac

hernia (Table 1) including this report. The true age of incidence of Amyand hernia for each patient is difficult to determine, as many patients do not present until pain or discomfort reaches high levels, often many years after hernia formation. Additionally, some cases of left-sided Amyand hernia described herein, including our case, are recurrent cases of a previous hernia that have been surgically repaired. ${ }^{2-20}$

Presentation of Amyand hernia often resembles that of a complicated inguinal hernia, acute appendicitis, or both. Hence, clinicians should consider this a possibility when patients present with signs and symptoms that could otherwise be thought to be originating from an incarcerated, strangulated, or recurrent hernia. Specifically, these signs and symptoms include a ten-
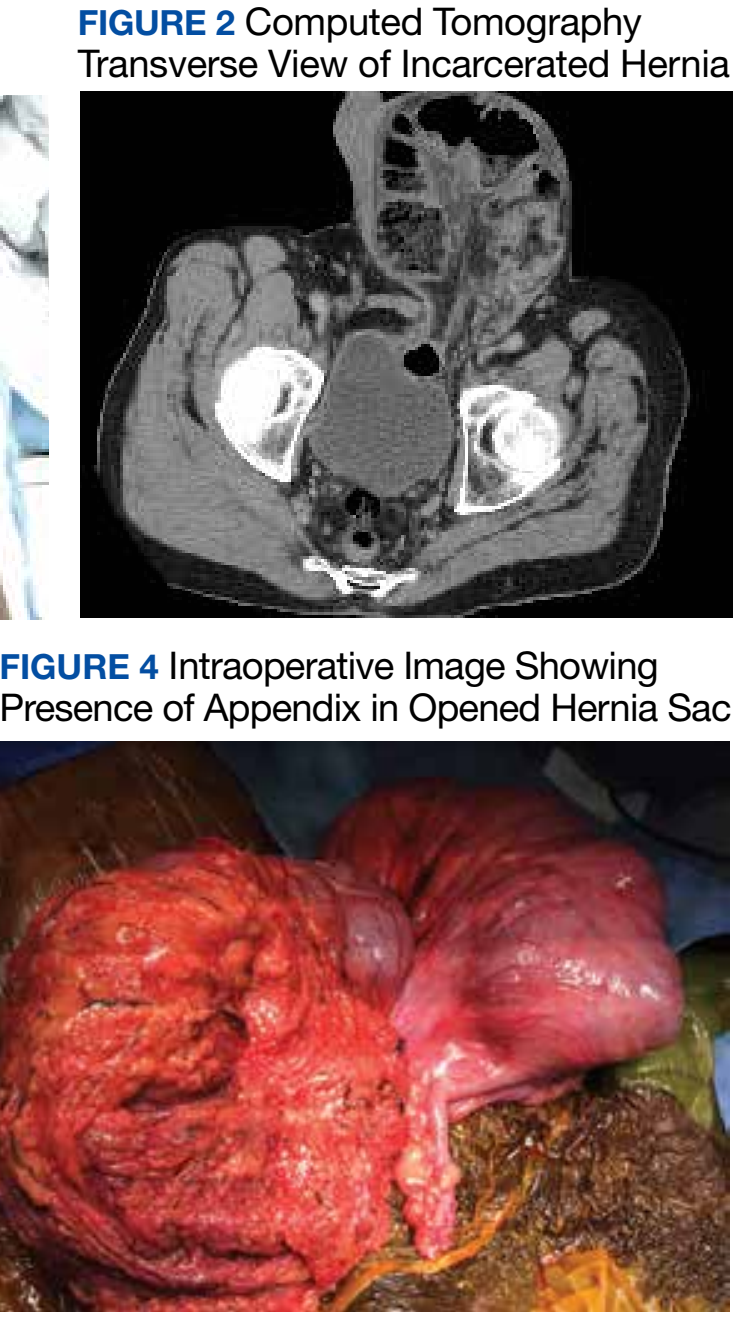

der, nonreducible mass in the inguinal region, acute lower abdominal pain, nausea, or signs of intestinal obstruction such as failure to produce bowel movements. ${ }^{4,17} \mathrm{Be}$ cause of the unusual anatomy in patients presenting with left-sided Amyand hernia, tenderness at the McBurney point usually is absent and not a useful diagnostic tool to rule out acute appendicitis.

A literature review indicates that an Amyand hernia on either side tends to occur in males more often than it does in females. The rate of diagnosis of Amyand hernia also has been reported to be 3 times higher in children than it is in adults due to failure of the processus vaginalis to obliterate during development. ${ }^{21}$ Our literature review supports this finding, as 16 of the documented 25 cases of left-sided Amyand hernia were reported in males. Additionally, information 
TABLE 1 Case Reports of Left-Sided Amyand Hernia

\begin{tabular}{|c|c|c|c|c|}
\hline Case Report & Year & Age, Gender & $\begin{array}{l}\text { Diagnosis (On Preoperative } \\
\text { Imaging or Intraoperatively) }\end{array}$ & $\begin{array}{c}\text { Treatment (Hernia } \\
\text { Repair and/or Appendectomy) }\end{array}$ \\
\hline Carey et $\mathrm{al}^{2}$ & 1967 & Not specified & Not specified & Not specified \\
\hline $\begin{array}{l}\text { Kaymakci et al }{ }^{3} \\
\text { ( } 3 \text { cases) }\end{array}$ & 1998-2009 & Not specified & Intraoperative & $\begin{array}{l}\text { Variable based on presence of } \\
\text { inflammation }\end{array}$ \\
\hline $\begin{array}{l}\text { Cankorkmaz et al }{ }^{4} \\
(2 \text { cases) }\end{array}$ & $1998-2006$ & $\begin{array}{l}2 \mathrm{mo}, \text { not specified } \\
4 \mathrm{mo} \text {, not specified }\end{array}$ & $\begin{array}{l}\text { Intraoperative } \\
\text { Intraoperative }\end{array}$ & $\begin{array}{l}\text { Variable based on presence of } \\
\text { inflammation }\end{array}$ \\
\hline Yasumoto et al ${ }^{5}$ & 1998 & $10 \mathrm{y}, \mathrm{M}$ & Intraoperative & Hernia repair + appendectomy \\
\hline Bakhshi et al ${ }^{6}$ & 2004 & Not specified & Not specified & Not specified \\
\hline Breitenstein et $\mathrm{al}^{7}$ & 2005 & $81 \mathrm{y}, \mathrm{F}$ & Intraoperative & Hernia repair + appendectomy \\
\hline Gupta et $\left.a\right|^{8}$ & 2005 & $9 \mathrm{mo}, \mathrm{M}$ & Intraoperative & Hernia repair + appendectomy \\
\hline Gupta et $\mathrm{al}^{9}$ & 2007 & $11 \mathrm{mo}, \mathrm{M}$ & Intraoperative & Not specified \\
\hline Tayade et $\mathrm{al}^{10}$ & 2008 & $34 \mathrm{y}, \mathrm{M}$ & Intraoperative & $\begin{array}{l}\text { Hernia repair + quartercolectomy + } \\
\text { ileoascending colon anastomosis }\end{array}$ \\
\hline Johari et al ${ }^{11}$ & 2009 & $70 \mathrm{y}, \mathrm{M}$ & Intraoperative & Hernia repair + appendectomy \\
\hline Malik et al ${ }^{12}$ & 2010 & $64 \mathrm{y}, \mathrm{M}$ & Intraoperative & $\begin{array}{c}\text { Hernia repair + Right hemicolectomy } \\
+ \text { + ileocolic anastomosis }\end{array}$ \\
\hline Ravishankaran et al ${ }^{13}$ & 2010 & $35 \mathrm{y}, \mathrm{M}$ & Intraoperative & Hernia repair + appendectomy \\
\hline $\begin{array}{l}\text { Singh et al }{ }^{14} \\
\text { ( } 2 \text { cases) }\end{array}$ & $\begin{array}{l}2011 \\
2011\end{array}$ & $\begin{array}{l}18 \mathrm{mo}, \mathrm{M} \\
18 \mathrm{mo}, \mathrm{M}\end{array}$ & $\begin{array}{l}\text { Intraoperative } \\
\text { Intraoperative }\end{array}$ & $\begin{array}{l}\text { Hernia repair } \\
\text { Hernia repair }\end{array}$ \\
\hline Khan et al ${ }^{15}$ & 2011 & $10 \mathrm{mo}, \mathrm{M}$ & Intraoperative & Hernia repair + appendectomy \\
\hline Ghafouri et al ${ }^{16}$ & 2012 & $60 \mathrm{y}, \mathrm{M}$ & Intraoperative & Hernia repair \\
\hline $\begin{array}{l}\text { Al-Mayoof et al }{ }^{17} \\
\text { ( } 2 \text { cases) }\end{array}$ & 2013 & $\begin{array}{c}3 \text { mo, M } \\
10 \text { mo, not specified }\end{array}$ & $\begin{array}{l}\text { Intraoperative } \\
\text { Intraoperative }\end{array}$ & $\begin{array}{l}\text { Hernia repair + appendectomy } \\
\text { Hernia repair + appendectomy }\end{array}$ \\
\hline Unver et a $\left.\right|^{18}$ & 2013 & $32 \mathrm{y}, \mathrm{M}$ & Preoperative computed tomography & Hernia repair + appendectomy \\
\hline Maeda et al ${ }^{19}$ & 2014 & $62 \mathrm{y}, \mathrm{M}$ & Intraoperative & Hernia repair \\
\hline Mongardini et $\mathrm{al}^{20}$ & 2015 & $68 \mathrm{y}, \mathrm{M}$ & Intraoperative & Hernia repair + appendectomy \\
\hline This report & 2019 & $62 \mathrm{y}, \mathrm{M}$ & Intraoperative & Hernia repair \\
\hline
\end{tabular}

regarding gender was not found in 6 cases, suggesting a potential for an even higher prevalence in males.

Explanations as to why the appendix is on the left side in these patients include developmental anomalies, such as situs inversus, intestinal rotation, mobile cecum, or an abnormally long appendix. ${ }^{3,8}$ In our case, the likely causative culprit was a mobile cecum, as there was neither indication of intestinal malformation, rotation, nor of an abnormally long appendix during surgery. Additionally, pre-operative radiologic studies, clinical evaluation, and electrocardiogram did not suggest the presence of situs inversus.

Treatment of Amyand hernia usually follows the landmark classification algorithm set forth in 2007 by Losanoff and Basson (Table 2). ${ }^{22}$ This system stratifies treatment based on intraoperative findings of the appendix and surrounding structures, ranging from type 1, which involves a normal appendix within the hernia, to type 4 , which includes acute appendicitis with additional abdominal pathology. Our patient presented with a type 1 Amyand hernia and appendectomy was foregone as per the guidelines; however, there have been numerous reported cases of surgeons opting for prophylactic appendectomy in the case of a normal appearing appendix and surrounding structures. The decision to act independent of the Losanoff and Basson classification underscores the lack of true standardization, 
namely, when it comes to a treatment approach for type 1 Amyand hernias. Nonetheless, many contend that indiscriminately performing appendectomies in all cases of left-sided Amyand hernia is useful as a prophylactic measure, as cases of future appendicitis in these patients will have atypical presentations based on the contralateral location of the appendix. ${ }^{6,11,17}$

Others disagree, citing that prophylactic appendectomy in the case of a normal looking appendix is unnecessary and complicates an otherwise sterile surgery (clean wound classification) with the removal of an appendix containing fecal matter and gut microbiota (converted into a clean contaminated or a contaminated wound classification). ${ }^{17}$ Additionally, it is thought that in the cases of middle-aged or geriatric patients where the chances of appendicitis are far less, the risks of detriment from prophylactic appendectomy may outweigh the benefits. In these cases, a macroscopic view of the appendix based on visual examination during the operation should guide decision making. ${ }^{4}$

While the decision to remove a healthyappearing appendix remains contentious, the decision for or against placement of a heterogenous hernia mesh has proven to be binary, with near universally accepted criteria. If signs of perforation or infection are present in the hernia sac, then surgeons will forego hernioplasty with mesh for simple herniorrhaphy. This contraindication for mesh placement is due to the increased risk of mesh infection, wound infection, and fistulae associated with the introduction of a foreign structure to an active infection site. ${ }^{2}$

While most cases of Amyand hernia are diagnosed intraoperatively, there have been documented cases of preoperative diagnosis using ultrasonography and CT imaging modalities. ${ }^{19,23,24}$ In all cases, the presence of the vermiform appendix within the hernia sac can complicate diagnosis and treatment, and preoperative knowledge of this condition may help to guide physician decision making. Identifying Amyand hernia via CT scan is not only useful for alerting physicians of a potentially inflamed appendix within the hernia sac, but also may create opportunities for the use of other treatment modalities. For example, laparoscopic Amyand hernia reduction, an approach that was
TABLE 2 Amyand Hernia Classification and Treatment Decision Tree 23

\begin{tabular}{lll}
\hline Classifications & Descriptions & Surgical Management \\
\hline Type 1 & $\begin{array}{l}\text { Normal appendix in } \\
\text { an inguinal hernia }\end{array}$ & $\begin{array}{l}\text { Hernia reduction, tension-free } \\
\text { herniorrhaphy with mesh }\end{array}$ \\
\hline Type 2 & $\begin{array}{l}\text { Acute appendicitis in } \\
\text { an inguinal hernia with } \\
\text { no abdominal sepsis }\end{array}$ & $\begin{array}{l}\text { If hernia is reducible, antibiotic } \\
\text { treatment; can be followed by interval } \\
\text { herniorrhaphy with mesh or interval } \\
\text { appendectomy with herniorrhaphy with } \\
\text { or without mesh } \\
\text { If the hernia is acutely incarcerated, } \\
\text { appendectomy with herniorrhaphy } \\
\text { without mesh or with biologic mesh }\end{array}$ \\
\hline Type 3 & $\begin{array}{l}\text { Acute appendicitis in } \\
\text { an inguinal hernia with } \\
\text { abdominal and } \\
\text { abdominal wall sepsis }\end{array}$ & $\begin{array}{l}\text { Appendectomy and herniorrhaphy with } \\
\text { biologic mesh or without mesh }\end{array}$ \\
\hline Type 4 & $\begin{array}{l}\text { Acute appendicitis } \\
\text { in an inguinal hernia } \\
\text { with abdominal } \\
\text { concomitant pathology }\end{array}$ & $\begin{array}{l}\text { Identical to type } 3 \text { plus management of } \\
\text { concomitant disease }\end{array}$ \\
\hline
\end{tabular}

performed successfully and documented for the first time by Vermillion and colleagues, was made possible by preoperative diagnosis and can potentially result in improved patient outcomes. ${ }^{25}$

Regardless, while standardization of treatment for Amyand hernia has not yet occurred, it is clear that improved preoperative diagnosis, especially in the case of an unanticipated left-sided Amyand hernia, can allow for better planning and use of a wider variety of treatment modalities. The main impediment to this approach is that suspected cases of appendicitis and inguinal hernias (the most common preoperative diagnoses of Amyand hernia) usually are diagnosed clinically without the need of additional imaging studies like CT or ultrasound. In accordance with the guiding principle of radiation safety of exposing patients to "as low as reasonably achievable" (ALARA) radiation and with consideration of expediency of care and cost efficiency, we recommend physicians continue to screen for and treat cases of potentially emergent appendicitis and/or inguinal hernia as per the conventional methodology. The best approach may involve increasing preoperative diagnoses of left-sided Amyand hernias via physician awareness of this rare finding, as well as evaluating imaging studies that have previously been obtained in order to narrow a broad differential diagnosis. 


\section{CONCLUSIONS}

Left-sided Amyand hernia is an exceptionally rare condition whose preoperative diagnosis remains difficult to establish but whose treatment decision tree is significantly impacted by the condition.

\section{Author disclosures}

The authors report no actual or potential conflicts of interest with regard to this article.

\section{Disclaimer}

The opinions expressed herein are those of the authors and do not necessarily reflect those of Federal Practitioner, Frontline Medical Communications Inc., the US Government, or any of its agencies.

\section{References}

1. Franko J, Raftopoulos I, Sulkowski R. A rare variation of Amyand's hernia. Am J Gastroenterol. 2002;97(10):26842685. doi:10.1111/j.1572-0241.2002.06060.x

2. Carey LC. Acute appendicitis occurring in hernias: a report of 10 cases. Surgery. 1967;61(2):236-238.

3. Kaymakci A, Akillioglu I, Akkoyun I, Guven S, Ozdemir A, Gulen S. Amyand's hernia: a series of 30 cases in children. Hernia. 2009;13(6):609-612. doi:10.1007/s10029-009-0528-8

4. Cankorkmaz L, Ozer H, Guney C, Atalar MH, Arslan MS, Koyluoglu G. Amyand's hernia in the children: a single center experience. Surgery. 2010;147(1):140-143. doi:10.1016/j.surg.2009.09.038

5. Yasumoto R, Kawano M, Kawanishi $\mathrm{H}$, et al. Left acute scrotum associated with appendicitis. Int J Urol. 1998;5(1):108110. doi:10.1111/j.1442-2042.1998.tb00254.x

6. Bakhshi GD, Bhandarwar AH, Govila AA. Acute appendicitis in left scrotum. Indian J Gastroenterol. 2004;23(5):195.

7. Breitenstein S, Eisenbach C, Wille G, Decurtins M. Incarcerated vermiform appendix in a left-sided inguinal hernia Hernia. 2005;9(1):100-102. doi:10.1007/s10029-004-0263-0

8. Gupta S, Sharma R, Kaushik R. Left-sided Amyand's hernia. Singapore Med J. 2005;46(8):424-425.

9. Gupta N, Wilkinson TV, Wilkinson A, Akhtar M. Leftsided incarcerated Amyand's hernia. Indian J Surg. 2007;69(1):17-18

10. Tayade, MB, Bakhshi GD, Borisa AD, Deshpande G, Josh N. A rare combination of left sided Amyand's and Richter's hernia. Bombay Hosp J. 2008;50(4): 644-645

11. Johari HG, Paydar S, Davani SZ, Eskandari S, Jo- hari MG. Left-sided Amyand hernia. Ann Saudi Med. 2009;29(4):321-322. doi:10.4103/0256-4947.55305

12. Ali SM, Malik KA, Al-Qadhi H. Amyand's Hernia: Study of four cases and literature review. Sultan Qaboos Univ Med J. 2012;12(2):232-236. doi:10.12816/0003119

13. Ravishankaran P, Mohan G, Srinivasan A, Ravindran G, Ramalingam A. Left sided amyand's hernia, a rare occurrence: A Case Report. Indian J Surg. 2013;75(3):247-248. doi:10.1007/s12262-010-0223-0

14. Singh K, Singh RR, Kaur S. Amyand's hernia. J Indian Assoc Pediatr Surg. 2011;16(4):171-172. doi:10.4103/0971-9261.86890

15. Khan TS, Wani ML, Bijli AH, et al. Amyand's hernia: a rare occurrence. Ann Nigerian Med. 2011;5(2):62-64. doi:10.4103/0331-3131.92955

16. Ghafouri A, Anbara T, Foroutankia R. A rare case report of appendix and cecum in the sac of left inguinal hernia (left Amyand's hernia). Med J Islam Repub Iran. 2012;26(2): 94-95.

17. Al-Mayoof AF, Al-Ani BH. Left-sided amyand hernia: report of two cases with review of literature. European J Pediatr Surg Rep. 2014;2(1):63-66. doi:10.1055/s-0033-1347131

18. Unver M, Ozturk S, Karaman K, Turgut E. Left sided Amyand's hernia. World J Gastrointest Surg. 2013;5(10):285286. doi:10.4240/wjgs.v5.i10.285

19. Maeda K, Kunieda K, Kawai M, et al. Giant left-sided inguinoscrotal hernia containing the cecum and appendix (giant left-sided Amyand's hernia). Clin Case Rep. 2014;2(6):254-257. doi:10.1002/ccr3.104

20. Mongardini M, Maturo A, De Anna L, et al. Appendiceal abscess in a giant left-sided inguinoscrotal hernia: a rare case of Amyand hernia. Springerplus. 2015;4:378. Published 2015 Jul 26. doi:10.1186/s40064-015-1162-9

21. Ivanschuk G, Cesmebasi A, Sorenson EP, Blaak C, Loukas M, Tubbs SR. Amyand's hernia: a review. Med Sci Monit. 2014;20:140-146. Published 2014 Jan 28. doi:10.12659/MSM.889873

22. Losanoff JE, Basson MD. Amyand hernia: what lies beneath--a proposed classification scheme to determine management. Am Surg. 2007;73(12):1288-1290.

23. Coulier B, Pacary J, Broze B. Sonographic diagnosis of appendicitis within a right inguinal hernia (Amyand's hernia). J Clin Ultrasound. 2006;34(9):454-457. doi:10.1002/jcu.20266

24. Vehbi H, Agirgun C, Agirgun F, Dogan Y. Preoperative diagnosis of Amyand's hernia by ultrasound and computed tomography. Turk J Emerg Med. 2016;16(2):72-74. Published 2016 May 8. doi:10.1016/j.tjem.2015.11.014

25. Vermillion JM, Abernathy SW, Snyder SK. Laparoscopic reduction of Amyand's hernia. Hernia. 1999;3:159-160. doi:10.1007/BF01195318 